\title{
In vivo and in vitro quantitative analysis of neural crest cell migration
}

Elias H Barriga ${ }^{1 \&}$, Adam Shellard ${ }^{1 \&}$ and Roberto Mayor ${ }^{1 *}$

${ }^{1}$ Cell and Developmental Biology Department, University College London, WC1E 6BT, London, United Kingdom.

\&Equal contribution

*Corresponding author: Roberto Mayor, e-mail: r.mayor@ucl.ac.uk

Key words: Neural crest cells; quantitative migration, in situ hybridization; Xenopus laevis; cell migration; cell dispersion; grafts; Delaunay-Voronoi triangulation; neural crest dissection. 
Abstract: The neural crest (NC) is an embryonic cell population induced at the border of the neural plate from where it delaminates and migrates long distances across the embryo. Due to its extraordinary migratory capabilities the NC has become a powerful system to study cellular and molecular aspects of collective and single cell migration both in vivo and in vitro. Here we provide detailed protocols used to perform quantitative analysis of molecular and cellular aspects of Xenopus laevis neural crest cell migration, both in vivo and in vitro. 


\section{Introduction:}

The neural crest (NC) is an embryonic cell population characterised by its multipotent and highly migratory capabilities. The NC is induced at the border of the vertebrate neural plate from where it migrates long distances to contribute to the formation of a wide range of tissues (1-3). NC has been widely used in the study of the mechanism by which inductive signals regulate development (4-6), but more recently it has become an outstanding model for the study of molecular and cellular aspects of single and collective cell migration (7-10). The migration of NC cells can be studied by using in vivo and in vitro approaches. In vivo experiments allow direct observation of the effect that the manipulation of a target molecule could have in the migration of the NC, whilst in vitro analysis provide more detailed information about specific cell behaviours which may be responsible for the phenotypes observed in vivo. Hence an optimal animal model for the study of NC migration should offer researchers the opportunity to perform in vivo and in vitro analysis.

Several animal models such as zebrafish, chicken, Xenopus and mouse have been used to study the migration of $\mathrm{NC}(6,11)$, but not all of them represent a strong platform to simultaneously approach in vivo and in vitro aspects of NC migration. Zebrafish, for instance, is excellent to study NC cell behaviour and gene function in vivo because it is easy to introduce genetic changes on its embryos, which are also transparent and easy to image (12). However, the isolation of NC cells for in vitro cultures is still a limiting factor. GFP-labelled zebrafish NC cells can be sorted by FACS and cultured in vitro (13), but upon sorting they lose one of the main features of NC migration which is its collectiveness. Therefore, cell-to-cell interactions during collective NC migration cannot be studied in vitro. Mice and chick embryos have been used to study NC development in vivo and in vitro (14), but these models also have limitations when it comes to the comparative analysis of in vivo vs in vitro NC migration. For example, chick and mice NC cell culture relies on a dissection that harvests varying amounts of NC, which not always represents a clonally homogeneous cell population $(6,11,15)$.

Xenopus laevis is a good model to study NC cell migration by combining both in vivo and in vitro experiments. Xenopus NC is well characterised and there is a wide 
range of markers that allow direct observation of its migration in vivo by standard in situ hybridization protocols. Due to its very easy manipulation, Xenopus NC cell behaviour can also be assessed in vivo by grafting labelled NC into unlabelled hosts and tracking its migration by time-lapse microscopy. Therefore, the effect of the gainor loss-of-function of a target molecule in NC migration can be easily assessed in vivo. Complementarily, the NC can be easily explanted from the embryo and cultured in vitro in a basic and low cost culture medium. This is particularly useful since most of cellular processes and behaviours observed in vivo e.g. collectiveness, fluidity, chase and run, contact inhibition of locomotion, response to chemoattractants, coattaction etc., are well conserved in vitro (7,16-23). Likewise, individual cell migration can be analysed by dissociating NC explants. Another advantage is that both in vivo and in vitro samples can be fixed after live imaging, so additional protein analysis can be performed, thereby optimizing the amount of data that can be extracted from

a single set of experiments. Here we provide detailed methods for qualitative and quantitative analysis of Xenopus laevis cranial neural crest migration in vivo and in vitro.

\section{Materials:}

\section{1 in vivo analysis of NC migration:}

\subsubsection{Embryo medium}

All Normal Amphibian Media (NAM) solutions need to be autoclaved before use.

1. NAM A (10x, keep at RT): for 1 litre use $64.28 \mathrm{~g} \mathrm{NaCl}, 1.49 \mathrm{~g} \mathrm{KCl}, 2.36 \mathrm{~g}$ $\mathrm{Ca}\left(\mathrm{NO}_{3}\right)_{2}, 1.2 \mathrm{~g} \mathrm{MgSO}_{4}$, and $0.37 \mathrm{~g}$ Diasodium EDTA. Adjust volume to 1 litre with distilled $\mathrm{H}_{2} \mathrm{O}$.

2. NAM B (10x, keep at RT): for 1 litre use $7.16 \mathrm{~g} \mathrm{Na}_{2} \mathrm{HPO}_{4}$. Adjust volume to 1 litre with distilled $\mathrm{H}_{2} \mathrm{O}$, adjust to $\mathrm{pH} 7.5$.

3. NAM C (100x, keep at $\left.4^{\circ} \mathrm{C}\right)$ : for $100 \mathrm{ml}$ use $0.84 \mathrm{~g} \mathrm{NaHCO}_{3}$. Adjust volume to $100 \mathrm{ml}$ with distilled $\mathrm{H}_{2} \mathrm{O}$. 
4. NAM 1/10 (keep at RT): for 1 litre use $10 \mathrm{ml}$ NAM A, $10 \mathrm{ml}$ NAM B, $1 \mathrm{ml}$ of NAM $\mathrm{C}$, and streptomycin to a final concentration of $100 \mu \mathrm{g} / \mathrm{ml}$. Adjust volume to 1 litre with distilled $\mathrm{H}_{2} \mathrm{O}$.

5. NAM 3/8 (keep at RT): for 1 litre use $37 \mathrm{ml}$ NAM A, $37 \mathrm{ml}$ NAM B, $1 \mathrm{ml}$ NAM C, and streptomycin to a final concentration of $100 \mu \mathrm{g} / \mathrm{ml}$. Adjust volume to 1 litre with distilled $\mathrm{H}_{2} \mathrm{O}$.

\subsubsection{In situ hybridization}

1. MEMFA (MEM-formaldehyde): for $40 \mathrm{ml}$ use $4 \mathrm{ml} 1 \mathrm{M}$ MOPS (Sigma) pH 7.4, $4 \mathrm{ml}$ $10 \mathrm{mM} \mathrm{MgSO} 4$ (Sigma), $4 \mathrm{ml} 20$ mM EGTA (Sigma), and $4 \mathrm{ml}$ of 37\% Formaldehyde (Sigma). Adjust volume to $40 \mathrm{ml}$ with DEPC- $\mathrm{H}_{2} \mathrm{O}$. Alternatively, the same mix (MEM) without formaldehyde (FA) can be prepared at 10x, stored at RT, and FA can be added freshly before using.

2. PBT (PBS 0.1\% Tween-20): for $200 \mathrm{ml}$ use $20 \mathrm{ml}$ PBS 10X (Sigma), $200 \mu \mathrm{l}$ Tween-20 (Sigma). Adjust volume to $200 \mathrm{ml}$ with DEPC- $\mathrm{H}_{2} \mathrm{O}$.

3. Dehydration (100\% Methanol) and rehydration solutions: for $100 \mathrm{ml}$ of each

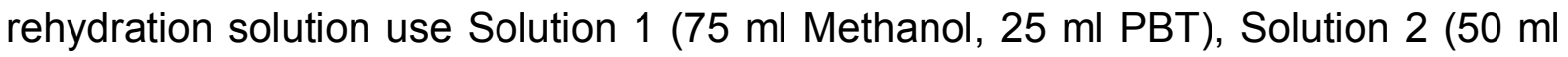
Methanol, $50 \mathrm{ml} \mathrm{PBT}$ ), Solution 3 (25 ml Methanol, $75 \mathrm{ml}$ PBT).

4. PBS-1x: for $200 \mathrm{ml}$ use $20 \mathrm{ml}$ PBS 10X (Sigma). Adjust volume to $200 \mathrm{ml}$ with DEPC- $\mathrm{H}_{2} \mathrm{O}$.

5. Bleaching solution (prepare fresh every time and to avoid explosions add $\mathrm{H}_{2} \mathrm{O}_{2}$ last): for $5 \mathrm{ml}$ use $250 \mu \mathrm{l}$ Formamide, $125 \mu \mathrm{l} 20 \mathrm{x} \mathrm{SSC}, 1 \mathrm{ml} \mathrm{H}_{2} \mathrm{O}_{2}$. Adjust the volume to $5 \mathrm{ml}$ with DEPC- $\mathrm{H}_{2} \mathrm{O}$.

6. Hybridization Buffer: for $500 \mathrm{ml}$ use $250 \mathrm{ml}$ Formamide, $125 \mathrm{ml}$ 20X SSC, $5 \mathrm{ml}$ Denhardt's Solution, $0.5 \mathrm{~g}$ Ribonucleic Acid, $0.05 \mathrm{~g}$ heparin, $0.5 \mathrm{~g}$ CHAPs, $1.86 \mathrm{~g}$ EDTA. Adjust volume to $500 \mathrm{ml}$ with of DEPC- $\mathrm{H}_{2} \mathrm{O}$. Heat at $60^{\circ} \mathrm{C}$ and agitate until dissolved. Take $5 \mathrm{ml}$ in a vial and test the $\mathrm{pH}$, it should be about $\mathrm{pH} 5.5$. Finally, add $0.1 \%$ of RNAse-free Tween-20, prepare $20 \mathrm{ml}$ aliquots and store at $-20^{\circ} \mathrm{C}$.

7. Probe washing solutions: for $100 \mathrm{ml}$ of each solution use Solution $1(75 \mathrm{ml}$ Formamide, $25 \mathrm{ml}$ 2X SSC, $100 \mu$ Tween), Solution 2 (50 ml Formamide, $50 \mathrm{ml}$ 2X SSC, $100 \mu$ T Tween), Solution 3 (25 ml Formamide, $75 \mathrm{ml} 2$ X SSC, $100 \mu$ l Tween), 
Solution 4 (100 ml 2X SSC, $100 \mu$ Tween), Solution 5 (100 ml 0.2X SSC, $100 \mu l$ Tween).

8. $20 \mathrm{X}$ SSC is commercially available and it is used to prepare $2 \mathrm{X}$ SSC and $0.2 \mathrm{X}$ SSC: for $100 \mathrm{ml}$ of $2 X$ SSC dilute $10 \mathrm{ml}$ of $20 X$ SSC in $90 \mathrm{ml}$ of DEPC- $\mathrm{H}_{2} \mathrm{O}$; for 100 $\mathrm{ml}$ of $0.2 X \mathrm{SSC}$, dilute $10 \mathrm{ml}$ of $2 X \mathrm{SSC}$ in $90 \mathrm{ml}$ of DEPC- $\mathrm{H}_{2} \mathrm{O}$ )

9. MAB: for $500 \mathrm{ml}$ use $5.81 \mathrm{~g}$ Maleic Acid, $4.38 \mathrm{~g} \mathrm{NaCl}$. Add $250 \mathrm{ml}$ distilled $\mathrm{H}_{2} \mathrm{O}$, adjust $\mathrm{pH}$ to 7.5 with solid $\mathrm{NaOH}$. Finally adjust volume to $500 \mathrm{ml}$ with distilled $\mathrm{H}_{2} \mathrm{O}$, autoclave and store at RT.

10. MAB-T: to $100 \mathrm{ml}$ of MAB, add $100 \mu$ of Tween-20.

11. Blocking Solution: prepare a 10X stock of Blocking reagent (Roche 11096176 001 ) by dissolving $10 \mathrm{~g}$ of blocking reagent in $100 \mathrm{ml}$ MAB. To prepare $10 \mathrm{ml}$ of blocking solution dilute $2 \mathrm{ml}$ of $10 x$ stock in $8 \mathrm{ml}$ of MAB.

12. Antibody solution: dilute $1 \mu \mathrm{l}$ of anti-digoxigenin alkaline phosphatase conjugate Fab fragments (Roche, 11093274910; $150 \mathrm{U}$ ) in $3 \mathrm{ml}$ of blocking solution.

13. Alkaline Phosphatase Buffer (AP buffer): for $50 \mathrm{ml}$ use $5 \mathrm{ml} 0.5 \mathrm{M} \mathrm{MgCl}_{2}, 5 \mathrm{ml}$ $1 \mathrm{M} \mathrm{NaCl}, 5 \mathrm{ml} 1 \mathrm{M}$ Tris- $\mathrm{HCl} \mathrm{pH} 9.5$ and $50 \mathrm{ml}$ Tween-20. Adjust volume to $50 \mathrm{ml}$ with distilled $\mathrm{H}_{2} \mathrm{O}$.

14. Colour development Solution: prepare NBT stock by dissolving $0.5 \mathrm{~g}$ of NBT (Rocher 11383213001, currently sold by Sigma) in a solution containing $30 \% \mathrm{H}_{2} \mathrm{O} / 70 \%$ N,N-Dimethylformamide (Sigma, 140732) and BCIP stock by dissolving $0.5 \mathrm{~g}$ of BCIP (Roche 11585002001, currently sold by Sigma) in $10 \mathrm{ml}$ of $\mathrm{N}, \mathrm{N}$-Dimethylformamide.

15. DEPC- $\mathrm{H}_{2} \mathrm{O}$ : for 1 litre add $1 \mathrm{ml}$ of $0.1 \%$ Diethylpyrocarbonate (DEPC) to 1 litre distilled or MilliQ water. Agitate for $10 \mathrm{~min}$, incubate overnight at RT and autoclave.

\subsubsection{Neural crest dissection and graft tools}

1. Embryo labelling: in addition to routine microinjection tools, this requires fluorescein dextran (FDX) or the following plasmids; pCS2-H2B-mCherry (red nuclear marker) and pCS2-mGFP (green membrane marker), or any other marker or methods that allows permanent fluorescent labelling of NC cells.

2. Eyebrow knife (Fig. 1a): to build an eyebrow knife, remove an eyebrow, embed the tip of a $150 \mathrm{~mm}$ glass Pasteur pipette (VWR 612-1701) in melted wax, and 
rapidly and before the wax solidifies, place the root of the eyebrow in the tip of the glass Pasteur pipette. You may prefer a rather short (3-5 $\mathrm{mm})$ eyebrow knife, as it will bend less during dissection.

3. Modelling clay dish (Fig. 1b): a glass dish filled with modelling clay. Fill a glass petri dish $100 \mathrm{~mm}$ x $20 \mathrm{~mm}$ (Corning, Inc. 3160-102BO) with modelling clay (dark green, blue, black, brown colours provide a better contrast).

4. Glass sphere (Fig. 1c): melt the tip of a $150 \mathrm{~mm}$ glass Pasteur pipette (VWR 6121701) and while melting, rotate the pipette on its own axis until you see a spherical tip.

5. $1 \times 1 \mathrm{~mm}$ micro-glass cover-slips: take a $0.1 \mathrm{~mm}$ thick coverslip and by using a Diamond Head glass cutter (Cutting ACT004), try to obtain 1 × $1 \mathrm{~mm}$ (approximately) pieces of glass.

6. Fine forceps Dumont \#5 (F.S.T. 11251-10) (Fig. 1d).

7. Dissecting microscope Leica MZFL III, equipped with a Leica DFC420 digital camera, Leica IM50 acquisition software and a gooseneck cold light source (Schott KL2500 Led), or equivalents.

\subsubsection{Statistical analysis}

1. ImageJ or Fiji.

2. For in situ hybridisation: lateral views of the control and injected sides of the embryos. For grafts: lateral view of the last frame of time-lapse acquisitions of control and treated grafts.

3. Statistical software (e.g. Excel).

\subsection{In vitro analysis of NC cell migration}

\subsubsection{Dish preparation}

1. Fibronectin (Sigma, F1141): aliquot at 10x (1 mg/ml for glass dishes; $100 \mu \mathrm{g} / \mathrm{ml}$ for plastic dishes), store at $-20^{\circ} \mathrm{C}$ and dilute in PBS.

2. $0.1 \%$ BSA/PBS: aliquot and store at $-20^{\circ} \mathrm{C}$.

4. PBS 1x (1L): $8 \mathrm{~g} \mathrm{NaCl}, 0.2 \mathrm{~g} \mathrm{KCl}, 1.44 \mathrm{~g} \mathrm{Na}_{2} \mathrm{HPO}_{4}, 0.24 \mathrm{~g} \mathrm{KH}_{2} \mathrm{PO}_{4}$. Adjust to $\mathrm{pH}$ 7.4 , autoclave and store at room temperature. 
5. Plastic (Falcon 351006) or glass (FluoroDish FD35-100) culture dishes.

6. Heat block set at $37^{\circ} \mathrm{C}$.

\subsubsection{Neural crest cell culture}

1. Danilchik's for Amy medium (DFA; 24): $53 \mathrm{mM} \mathrm{NaCl}, 5 \mathrm{mM} \mathrm{Na} \mathrm{CO}_{3}, 4.5 \mathrm{mM}$ KGluconate, $32 \mathrm{mM}$ NaGluconate, $1 \mathrm{mM} \mathrm{MgSO}_{4}\left(7 \mathrm{H}_{2} \mathrm{O}\right), 1 \mathrm{mM} \mathrm{CaCl} 2,0.1 \% \mathrm{BSA}$; adjusted to $\mathrm{pH} 8.3$ with $1 \mathrm{M}$ Bicine. Store at $-20^{\circ} \mathrm{C}$. After thawing, add $1000 \mathrm{U}$ penicillin and $100 \mu \mathrm{g} / \mathrm{ml}$ streptomycin.

2. $\mathrm{Ca}^{2+}$-free DFA: same as DFA, but without $\mathrm{CaCl}_{2}$ and $\mathrm{MgSO}_{4}$.

3. Fibronectin-coated dish and non-fibronectin-coated dish (untreated dish).

\subsubsection{Statistical analysis}

1. ImageJ or FIJI with plugins: Manual Tracking, Chemotaxis Tool, Dispersion Tool.

2. Time-lapse acquisition files, in stack format (rather than hyperstack).

\section{Methods:}

\section{1 in vivo analysis of neural crest cell migration}

\subsection{1 in situ hybridization}

This protocol can be applied to detect any NC probe (pre-migratory or migratory) and also other probes involved in different developmental processes of Xenopus laevis embryos. From steps 1-11, use RNase-free conditions.

Probe transcription

1. To transcribe probes we suggest using standard protocols from Promega Riboprobe ${ }^{\circledR}$ in vitro transcription systems (P1420 for Sp6, P1430 for T3 and P1440 for T7 RNA polymerases kit). But using Roche Dig RNA Labeling mix (Roche 11277 073 910, currently available from Sigma) instead ribonucleotides provided in the kit. After transcription use RNeasy Kit (Qiagen ID: 74104) to clean up the RNA and resuspend in RNase free $\mathrm{H}_{2} \mathrm{O}$ (Ambion AM9937, currently available from 
thermofisher). For Slug or Twist probes, dilute to $1 \mathrm{mg} / \mathrm{ml}$ in hybridization buffer for working solution.

Fixing and storing embryos

2. Carefully remove the vitelline membrane in NAM $3 / 8$ using fine forceps Dumont \#5 (F.S.T. 11251-10). Remove the vitelline membrane at st22 and allow the embryos to recover until they reach st23 (for slug probe) or st25 (for twist probe).

3. Rinse the embryos 2 times with fresh NAM $3 / 8$ and using a $3 \mathrm{ml}$ plastic Pasteur pipette (Scientific Laboratory Supplies, cat. no. PIP4210) transfer the embryos to a new RNase-free $2 \mathrm{ml}$ plastic tube (Sigma BR780546).

3. Remove the excess of NAM 3/8 (make sure the embryos are not dry) and rinse twice with $1 \mathrm{ml}$ of RNase-free PBS-1x.

4. Fixation: remove the PBS-1x and fix by adding $1 \mathrm{ml}$ of MEMFA for $2 \mathrm{hrs}$ at RT or overnight at $4^{\circ} \mathrm{C}$.

5. After fixation embryos can be stored in $100 \%$ Methanol at $-20^{\circ} \mathrm{C}$ for up to 6 months.

Day 1: Rehydration and Hybridization

6. Rehydration: rinse the embryos with $1 \mathrm{ml}$ of fresh methanol and rehydrate by successively incubating in rehydration solutions as follow: $3 \mathrm{~min}$ in $1 \mathrm{ml}$ solution 1,3 min in $1 \mathrm{ml}$ solution 2, $3 \mathrm{~min}$ in $1 \mathrm{ml}$ solution 3 , rinse twice in PBT and wash twice for 5 min in PBT.

7. Bleaching (optional): a bleaching step is recommended if using a probe that develop with a weak intensity or if a more defined signal is required. To bleach, incubate the embryos in $1.5 \mathrm{ml}$ of bleaching solution. Bleaching should be achieved in $25 \mathrm{~min}$ (if not, add fresh solution and wait). Monitor the bleaching and mix the embryos every 5 or 10 min. This bleaching works better if you let the tube to lay on its side on a piece of aluminium foil or by exposing the tube to a direct source of light.

8. Rinse 3 times in PBT and incubate in MEMFA for 20 min.

9. Pre-hybridization: rinse the embryos twice with PBT and once with hybridization buffer for $3 \mathrm{~min}$ at $65^{\circ} \mathrm{C}$ in a heat block. Incubate with hybridization buffer for at least $1 \mathrm{hr}$ at $65^{\circ} \mathrm{C}$ heat block. 
10. Hybridization: dilute the probe to $1 \mu \mathrm{g}$ of probe per $\mathrm{ml}$ of hybridization buffer and incubate for $10 \mathrm{~min}$ at $65^{\circ} \mathrm{C}$. Remove as much hybridization buffer as possible, add $300 \mu$ l of probe and incubate overnight at $65^{\circ} \mathrm{C}$.

Day 2: Probe washing and anti-body incubation.

11. Probe recovery: probes can be re-used for at least 5 times. Using RNase-free pipette tips remove the probe and store it at $-20^{\circ} \mathrm{C}$. Rinse twice with pre-heated at $65^{\circ} \mathrm{C}$ probe removing Solution 1.

12. Probe washes: pre-heat the probe washing solutions at $65^{\circ} \mathrm{C}$. Wash the probe by successively incubating in probe washing solutions as follow: $5 \mathrm{~min}$ at $65^{\circ} \mathrm{C}$ in $1 \mathrm{ml}$ of solution 1 , rinse in solution 2 and wash for $5 \mathrm{~min}$ in solution $2 \mathrm{~min}$ at $65^{\circ} \mathrm{C}$, rinse in solution 3 and wash for $5 \mathrm{~min}$ at $65^{\circ} \mathrm{C}$ in solution 3 , wash twice for $10 \mathrm{~min}$ at $65^{\circ} \mathrm{C}$ in solution 4, wash twice for 15 min at $65^{\circ} \mathrm{C}$ in Solution 5. Finally, wash twice in MAB-T for 3 min.

13. Blocking and antibody incubation: add $500 \mu$ of blocking solution and incubate for $1 \mathrm{hr}$ at RT. To incubate the antibody, replace the blocking solution by adding 300$500 \mu \mathrm{l}$ of antibody solution and incubate with overnight at $4^{\circ} \mathrm{C}$ (agitation is recommended, but not strictly necessary).

Day 3: Colour development, storing and imaging.

14. Antibody washes: rinse 3 times with MAB-T and wash 6 times with MAB-T for 10 min at RT with agitation. A rinse with MAB-T is recommended between each wash.

15. Colour development: wash the embryos twice in AP buffer for 5 min and add revealing solution. Signal as the observed in Fig. 2a should appear in about $20 \mathrm{~min}$. Keep monitoring embryos every 5 min some probes develop very fast when just transcribed.

16. Storing: after the colour development step, rinse the embryos twice in AP buffer and wash in MAB-T twice for $5 \mathrm{~min}$, dehydrate in $100 \%$ methanol for $10 \mathrm{~min}$ and keep in MEMFA or $4 \%$ formaldehyde (in MAB) for storage. 
17. Imaging: images can be acquired in a stereoscope, we use $3.2 x$ magnification in a Leica MZFL III stereoscope, equipped with a Leica DFC420 digital camera, Leica IM50 acquisition software and a gooseneck cold light source (Schott KL2500 Led). Embryos are held in a 2\% agarose dish. Make a hole in the agarose approximate the size of an embryos and use forceps to carefully orient the embryos in the desired position (lateral view for neural crest migration), adjust exposition and acquire image.

\subsubsection{Neural crest dissection and graft}

Dissection and grafting is performed in NAM 3/8

Neural crest dissection

1. Remove the vitelline membrane from embryos at stage 15 in NAM $3 / 8$ and leave them to recover until stage 16-17.

2. While the embryos recover, use the glass sphere to make a hole in the clay. This hole will hold the embryo while dissecting the NC.

3. Place the embryos into the modelling clay dish and fit them into the hole made in step 2 . Orient the embryo with fine forceps with the NC facing up and very carefully, using the glass sphere compress the clay around the embryo, just enough to hold it.

5. Exposing the NC: using the eyebrow knife, remove the pigmented layer which is covering the NC. To do this we recommend to insert the eyebrow knife underneath the epidermis parallel to the NC (no more than 2 or 3 layers deep) and from this position, move the eyebrow toward dorsal to lift the epidermis and expose the NC.

6. Explanting the NC: at this point the NC is easy to remove, with the eyebrow knife make one incision parallel to the NC from posterior to anterior, one in the posterior limit from ventral to dorsal and a similar one in the anterior limit (going too deep may risk contamination with mesoderm or would break the embryo exposing the archenteron). Finally, "shave" the NC off the embryo from ventral to dorsal.

7. The NC explant can now be used either for in vivo or in vitro experiments (for in vitro experiments please see 3.2).

Neural crest graft 
8. Remove the vitelline membrane from a labelled donor (injected with FDX or nRFP/mGFP, or any other fluorescent labelling) and a WT unlabelled host.

9. Repeat step 2, this time making two holes in the modelling clay, one in front the other (two embryos diameter away from each other). Additionally, place a $1 \times 1 \mathrm{~mm}$ piece of cover-slip next to the host embryo.

10. Remove the NC from the host embryo first and prepare it for receiving the donor NC. Take special care to remove as much host NC as you can, but not damaging the host embryo.

11. Remove the donor NC from the labelled embryo and with the eyebrow knife place it next to the host embryo, on top of the $1 \times 1 \mathrm{~mm}$ piece of coverslip.

12. Re-arrange the space of the host embryo in which you will graft the donor NC, if necessary, and place the donor NC in the host embryo with the eyebrow knife.

13. Place the $1 \times 1 \mathrm{~mm}$ piece of cover-slip on top of the graft, this will help to hold the graft while it heals. The cover-slip can be hold in place with the help of the modelling clay that surround the embryo.

14. Let the embryo heal for $20-30 \mathrm{~min}$ at RT or $40 \mathrm{~min}$ at $14.5^{\circ} \mathrm{C}$. Remove the piece of cover-slip and very carefully loosen the embryo from the modelling clay and transfer to fresh NAM $3 / 8$, pre-chilled to $14.5^{\circ} \mathrm{C}$.

15. Imaging of the graft. The migration can be followed by manually acquiring a picture of each embryo as described in 3.1.1-17, as many frames as needed. If a more detailed analysis is required (for instances, cell velocity or directionality, angle of migration, etc.), an automated time-lapse may be necessary. Briefly, prepare a $2 \%$ agarose dish with $1 \mathrm{~mm}$ thick lanes or any type of pocket that could hold the embryos, before filling the dish with NAM 3/8, add methylcellulose to the bottom of the lane or pocket. Orient the embryo in the pocket and set a time-lapse movie, movie timing will depend on the room temperature (check developmental table www.xenbase.org to calculate length).

\subsubsection{Quantitative analysis in vivo}

This is a very simple measurement that can be applied to either in situ hybridization or in vivo graft time-lapse results.

Setting scale in ImageJ 
1. Open your image of interest in ImageJ/FIJI, which should include a scale bar.

2. From the drawing tools, select "straight" line and draw a line across the scale bar. Ensure that the line spans the whole scale bar.

3. In the analysis tab select "set scale". Select "known distance" to be the nominal length of the scale bar (100 if the scale bar represents $100 \mu \mathrm{m}$ ), then in the "unit of length" option write "micron", select the box "Global" and click "ok" (do not close ImageJ/FIJI).

Measuring and comparing migrated distance from in situ hybridization results

4. With the "straight* line tool, draw a line along the dorso-ventral axis of a NC migratory stream (yellow brackets in Fig. 2 a,b,e and f) and in the Analyse tab, select Measure. This will provide a length measurement. Repeat this 3 times for each side of each embryo (control and treated sides).

5. Copy the results file to excel, and average the three measurements taken for each side of the embryo. Next, normalise the measurement of the averaged control side to the averaged treated side by dividing the treated side by the control side. The number should be close to 1 for embryos in which the injected side was a control treatment and below 1 in the case the treatment has inhibited migration. Significance is calculated by using a parametric test as shown in Fig. 2c. The percentage of embryos displaying each phenotype is presented as shown in Fig. $2 \mathrm{~d}$.

Measuring and comparing migrated distance from in vivo graft results

In graft experiments, control and treated NC are not in the same embryo and NC migration cannot be compared as described for in situ hybridization results.

1. To normalise NC migration in grafted embryos, divide the dorso-ventral length of the NC stream by the dorso-ventral length of the embryo. Lengths are obtained and compared as described in steps 4-5. Significance is calculated by using a parametric test and data is represented as shown in Fig. $2 \mathrm{~g}$. The percentage of embryos displaying each phenotype is presented as shown in Fig. $2 \mathrm{~h}$. 


\subsection{In vitro analysis of NC migration:}

\subsubsection{Fibronectin-coated dish}

1. For plastic culture dishes, dilute the fibronectin to $10 \mu \mathrm{g} / \mathrm{ml}$ in PBS; for glass culture dishes, dilute the fibronectin to $100 \mu \mathrm{g} / \mathrm{ml}$ (see Note 1). Use a p20 pipette to transfer neural crest explants into a plastic dish filled with DFA. Ensure that the pipette tip has no air bubbles and that the neural crest remains in solution at all times.

2. Incubate the dish at $37^{\circ} \mathrm{C}$ on a heating block for one hour with the lid on or overnight at $4^{\circ} \mathrm{C}$.

3. Remove the fibronectin solution and rinse 2 times with PBS.

4. Replace with $0.1 \%$ BSA/PBS and incubate at $37^{\circ} \mathrm{C}$ on a heating block for $30 \mathrm{~min}$ with the lid on.

5. Rinse 2 times with PBS.

6. Fill the dish with chilled DFA.

\subsubsection{Neural crest culture}

1. Dissect the neural crest in 3/8 NAM, as described in 3.1.2.

2. Immediately after dissection, transfer the NC explants to the fibronectin-coated dish (see Note 2).

3. For a dispersion assay, use the hair knife to place neural crest explants at least 5 explants' distance away from each other (see Note 3).

4. For a single cell migration assay, cut explants into small pieces and then transfer them into a dish filled with Ca2+-free DFA.

5. After dissociation, transfer the neural crest cells to the fibronectin-coated dish (see Note 4).

6. Allow 1 hour for neural crest explants or cells to fully attach and begin spreading on the surface (in the case of explants).

7. Fill the plastic dish fully with DFA, such that the meniscus reaches the border of the dish and place the lid on.

8. Place the lid on, ensuring there are no air bubbles trapped inside (see Note 5).

9. Perform time-lapse imaging (see Note 6). 


\subsubsection{Neural crest dispersion analysis}

Note that the following method is for the Dispersion Tool plugin developed at Prof Roberto Mayor's laboratory and it is available upon request. This plugin works as of FIJI v1.51g and Java8.

1. Import the time-lapse acquisition file to ImageJ (see note 10).

2. Select the frame that you wish to analyse.

3. Under the 'Analyse' tab, select 'Set Measurements...' and ensure 'Area' is checked.

4. Open the 'Dispersion Tool' plugin. This will duplicate the frame selected, and open up a settings wizard.

5. Select your Dispersion Tool settings. 'Auto-save files' will save the output files to the save folder as the time-lapse acquisition folder. 'Create colorised mesh' will create a diagrammatic representation of your dispersion that shows cell position and triangulation area based on a colour scheme. This colour scheme can be changed under LUT; likewise, the triangle line colour can be changed. It is recommended to use the 0-800 pixel area range to be coloured initially. This can be easily changed afterwards if the triangle numbers are skewed outside of this range.

6. Hold shift and select all cells by successively clicking (Fig. 3a). Ideally, you will have a nuclear marker to identify cell position, if not the centroid of each cells can be used. Each point of selection will have an associated number tag beside it. Press OK when done.

7. The following output files will be provided; a 'Results' file that named 'Triangle Areas' that provides the area of each triangle by Delaunay triangulation (Fig. 3b). Note that the first line will show the total sum area of all of the triangles. An "Overlay" file shows the selected cells and triangles overlaid onto the original file image, and can be used as a reference (Fig. 3c). A "Distance" file will be created that shows the average cell distance from each other from the Delaunay triangulation, as well as standard deviation and standard deviation of the mean. This distance is a more direct measure of dispersion. A more sensitive/intuitive method is the triangle areas. The ROI selection file will provide the points selected that can be changed, replot or reloaded into the Dispersion Tool. Finally, there will be a Mesh file that 
diagrammatically represents the dispersion based on the colour-code of the LUT selected (Fig. 3c).

8. To present this data, it is recommended to show the nuclei position of representative example NC cell explants (Fig. 3d, e), colorised triangulation diagrams of these (Fig. 3d', e'), and graphical quantification of the triangle areas based on all explants from the experiment(s) (Fig. 3f). This can be derived from the individual triangle areas (Fig. 3b).

Alternatively, Delaunay-Voronoi ImageJ/FIJI plugin can be used.

\subsubsection{Single cell migration analysis}

1. Import the necessary frames of the time-lapse acquisition file to ImageJ.

2. Open the 'Manual Tracking' plugin.

3. Click 'add track' and proceed to click on the same cell for every frame of the file (Fig. $3 g$ ). The nucleus should be used as the reference for tracking (as described in Section 2.1.3). Moreover, cells should only be tracked for the periods in which they do not contact other cells. Tick 'show paths' to review cell tracks.

4. Once the track is complete, click 'End track' and save the results file which appears in a separate window (see Note 13).

5. Open the 'Chemotaxis and Migration Tool'. Click 'Import data' and select the saved tracks file.

6. Beside 'Number of slices', select 'Use slice range from.. to.." and enter the first frame number and last frame number of the time-lapse file used for the cell tracking. Click 'Add dataset'. Repeat this step for all data files.

7. Beside 'Selected Dataset 1', select the imported file name that you wish to get statistics from, and check the box. Likewise, can be done for up to four files at a time. Click 'Apply Settings'.

8. Select the 'Settings' tab and enter the time interval (the pass time), and the $X / Y$ calibration based on the microscope and objective used. Click 'Apply Settings'.

9. Select the tab 'Statistic feature' and select 'velocity' (Fig. 3j). Each line provides the velocity of that cell track in pixels, unless a calibration is set. The Chemotaxis Tool plugin also allows quantification of the forward migration index (Fig. 3h), Eucledian distance (Fig. 3i), directionality (Fig. 3k) and accumulated distance (Fig. 3I). This method can also be applied for collective NC cell migration (see Note 7). 


\section{Notes or Hints:}

1. To avoid surplus fibronectin use, we first mark on a smaller area on the underside of the culture dish using a marker pen, and add the fibronectin only to this area rather than the whole dish.

2. For experiments, neural crest explants with different conditions should be plated onto the fibronectin dishes at the same time, and all explants should be similar in size. For this, neural crest explants can first be kept in a DFA dish not coated with fibronectin. After all embryos have been dissected, use the hair knife to cut explants into equally sized pieces, before transferring them to the fibronectin dish.

3. If performing time-lapse imaging with multiple position using a motorized stage for multiple neural crest explants, it is recommended to organise explants in rows.

4. Transfer the neural crest cells as soon as they have dissociated, because low $\mathrm{Ca} 2+$ induce apoptosis if kept in the solution for too long. Dissociation should take approximately $5 \mathrm{~min}$. Use the hair knife to push the transferred neural crest cells to the bottom of the fibronectin-coated dish.

5. When using an upright microscope, ensure that there are no air bubbles in the dish, which will have to be flipped. Laying grease around the area that contains the neural crest cells is useful if the dish has to be flipped for an upright microscope, because any air bubbles trapped inside will stick to the grease without damaging the neural crest cells.

6. For the dispersion assay, 18-hour time-lapse imaging with a pass time of $10 \mathrm{~min}$ is recommended. For the single cell migration assay, a 3 or 5 min pass time is recommended. Focus should be set to the cell's nuclear marker. In the case of neural crest explants, which have multiple cell layers in the centre of the explants, set the focus to the nuclei at the edge. It is recommended to acquire bright field, nuclei and membrane channels. For Xenopus laevis neural crest, it is recommended to have a room temperature of $17^{\circ} \mathrm{C}$.

7. For the tracking of cell groups, two tracks can be analysed: the individual cells based on nuclear positioning, and/or the centre of the cluster, to analyse the behaviour of the group as a singular unit. Data will likely be normally distributed, with wild type neural crest migrating at a speed of approximately $2+/-1 \mu \mathrm{m} / \mathrm{min}$, although cell velocity is hugely dependent on temperature. 


\section{Acknowledgments:}

This study was supported by grants from MRC (M010465 and J000655) and BBSRC (M008517) and Wellcome Trust to R.M, by a Long Term EMBO Fellowship and a Marie Curie Fellowship (329968) to E.B. and a Wellcome Trust fellowship to A. S. 


\section{References:}

1. Barriga EH, Mayor R (2015) Embryonic Cell-Cell Adhesion: A Key Player in Collective Neural Crest Migration. Curr Top Dev Biol 112:301-23

2. Green S, Simoes-Costa M, Bronner ME (2015) Evolution of vertebrates as viewed from the crest. Nature 520:474-482

3. Dupin E, Sommer L (2012) Neural crest progenitors and stem cells: From early development to adulthood. Dev Biol 366:83-95

4. Steventon B, Carmona-Fontaine C, Mayor R (2005) Genetic network during neural crest induction: from cell specification to cell survival. Semin Cell Dev Biol 16: 647654

5. Rogers CD, Jayasena S, Nie S, Bronner ME (2012) Neural crest specification: tissues, signals, and transcription factors. WIREs Dev Biol 1:52-68.

6. Milet C, Monsoro-burq AH (2012) Neural crest induction at the neural plate border in vertebrates. Dev Biol 366:22-33

7. Barriga EH, Maxwell PH, Reyes AE, Mayor R (2013) The hypoxia factor Hif-1 $\alpha$ controls neural crest chemotaxis and epithelial to mesenchymal transition. J. Cell Biol 201:759-776

8. Richardson J, Gauert A, Briones Montecinos L, Fanlo L, Alhashem ZM, Assar R, Marti E, Kabla A, Hartel S, and Linker C (2016) Leader Cells Define Directionality of Trunk, but Not Cranial, Neural Crest Cell Migration. Cell Reports 15:2076-2088.

9. Simoes-Costa M, Bronner ME (2016) Reprogramming of avian neural crest axial identity and cell fate. Science 352:1570-1573

10. Theveneau E, Mayor R (2012) Neural crest delamination and migration: From epithelium-to-mesenchyme transition to collective cell migration. Dev Biol 366:34-54 11. Barriga EH, Trainor PA, Bronner ME, Mayor R (2015) Animal models for studying neural crest development: is the mouse different? Development 142:1555-1560

12. Elks PM, Renshaw SA, Meijer AH, Walmsley SR, van Eeden FJ (2015) Exploring the HIFs, buts and maybes of hypoxia signalling in disease: lessons from zebrafish models. Dis Mod \& Mech 8:1349-1360

13. Kinikoglu B, Kong Y, Liao EC (2014) Characterization of cultured multipotent zebrafish neural crest cells. Exp Biol Med 239:159-168

14. Trainor PA (2005) Specification of neural crest cell formation and migration in mouse embryos. Semin Cell Dev Biol 16:683-693 
15. Etchevers H (2011) Primary culture of chick, mouse or human neural crest cells. Nat Protocols 6:1568-1577

16. Carmona-Fontaine C, Matthews HK, Kuriyama S, Moreno M, Dunn GA, Parsons M, Stern CD, Mayor R (2008) Contact inhibition of locomotion in vivo controls neural crest directional migration. Nature 456:957-961

17. Carmona-Fontaine C, Theveneau E, Tzekou A, Tada M, Woods M, Page KM, Parsons M, Lambris JD, R Mayor (2011) Complement fragment C3a controls mutual cell attraction during collective cell migration. Dev Cell 21:1026-1037

18. Theveneau E, Marchant L, Kuriyama S, Gull M, Moepps B, Parsons M, Mayor R (2010) Collective chemotaxis requires contact-dependent cell polarity. Dev. Cell 19:39-53

19. Scarpa E, Szabó A, Bibonne A, Theveneau E, Parsons M, Mayor R (2015) Cadherin Switch during EMT in Neural Crest Cells Leads to Contact Inhibition of Locomotion via Repolarization of Forces. Dev Cell 34:421-434

20. Szabó A, Melchionda M, Nastasi G, Woods ML, Campo S, Perris R, Mayor R (2016) In vivo confinement promotes collective migration of neural crest cells. J Cell Biol 213:543-555

21. Theveneau E, Steventon B, Scarpa E, Garcia S, Trepat X, Streit A, Mayor R (2013) Chase-and-run between adjacent cell populations promotes directional collective migration. Nat Cell Biol 15:763-772

22. Kuriyama S, Theveneau E, Benedetto A, Parsons M, Tanaka M, Charras G, Kabla A, Mayor R (2014) In vivo collective cell migration requires an LPAR2dependent increase in tissue fluidity. J Cell Biol 206:113-27

23. Moore R, Theveneau E, Pozzi S, Alexandre P, Richardson J, Merks A, Parsons M, Kashef J, Linker C, Mayor R (2013) Par3 controls neural crest migration by promoting microtubule catastrophe during contact inhibition of locomotion. Development 140:4763-4775

24. Sater AK, Richard A, Steinhardt, Ray Keller (1993) Induction of Neuronal Differentiation by Planar Signals in Xenopus Embryos. Dev Dyn 197:268-280 
Figure legends.

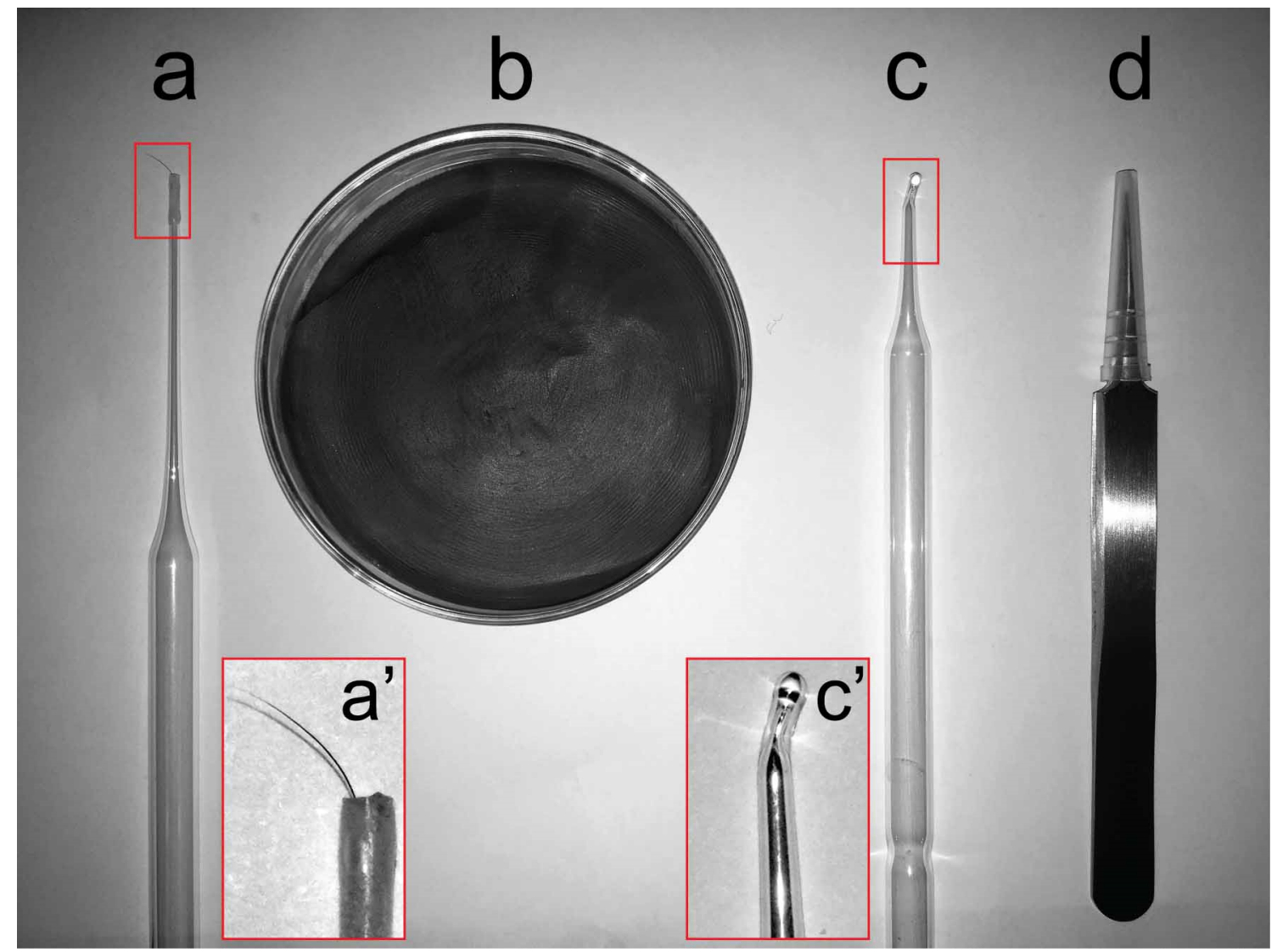

Figure 1. Tools used for neural crest dissection. (a) Eyebrow knife, (b) modelling clay dish, (c) glass sphere, and (d) fine forceps. a' eyebrow magnification from a, and c' glass sphere magnification from $\mathrm{c}$. 
Control

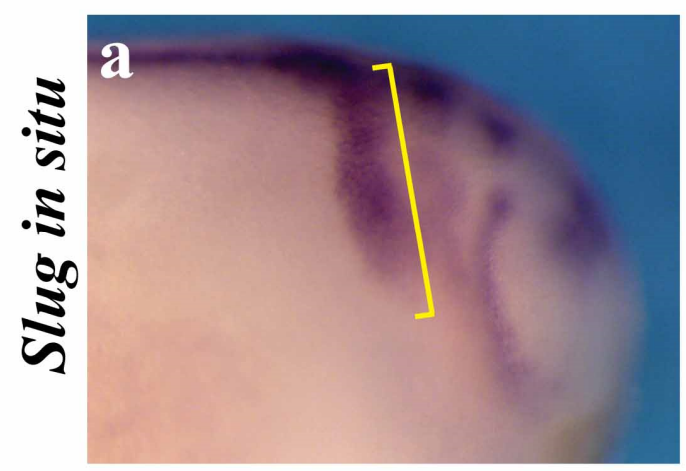

c

Normalised NC migration

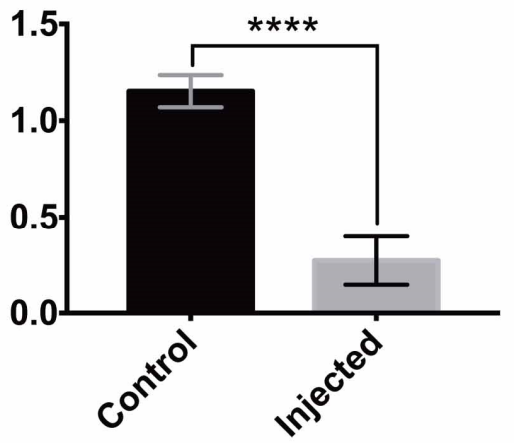

WT to WT

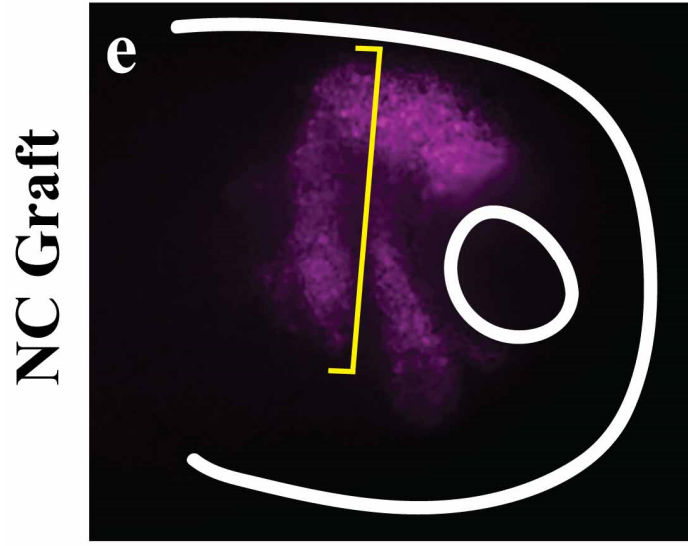

$\mathbf{g}_{\text {Normalised NC migration }}$

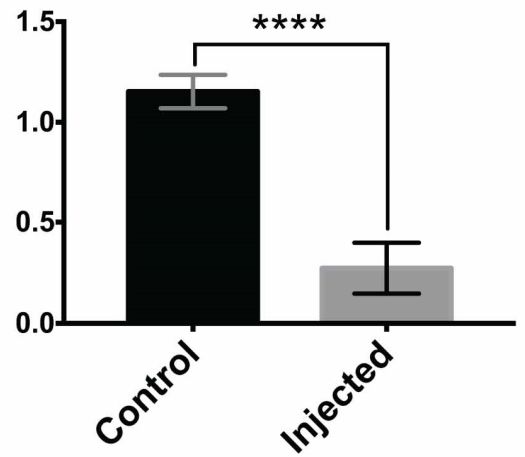

Injected

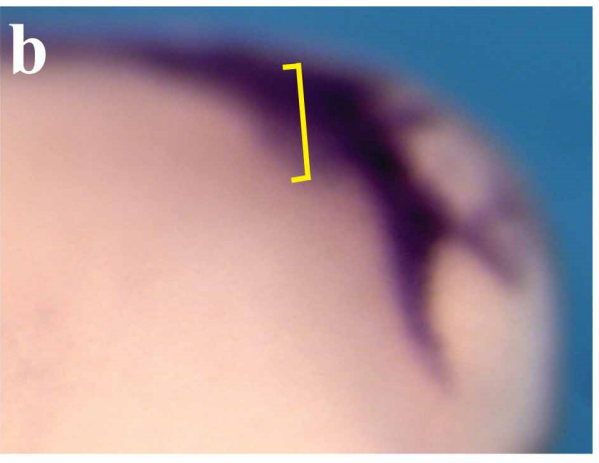

d

$\%$ NC Migration

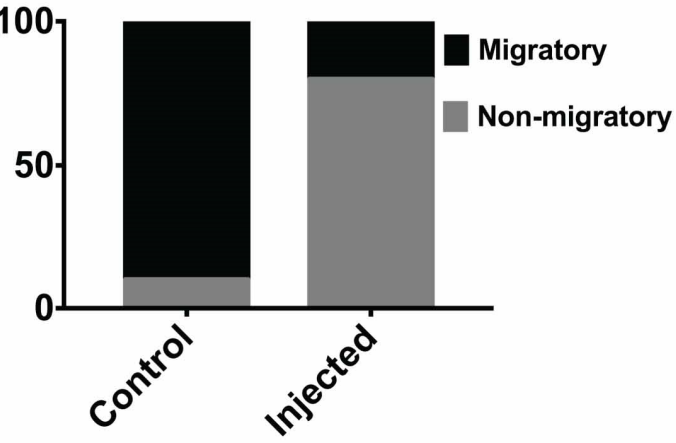

Injected to WT

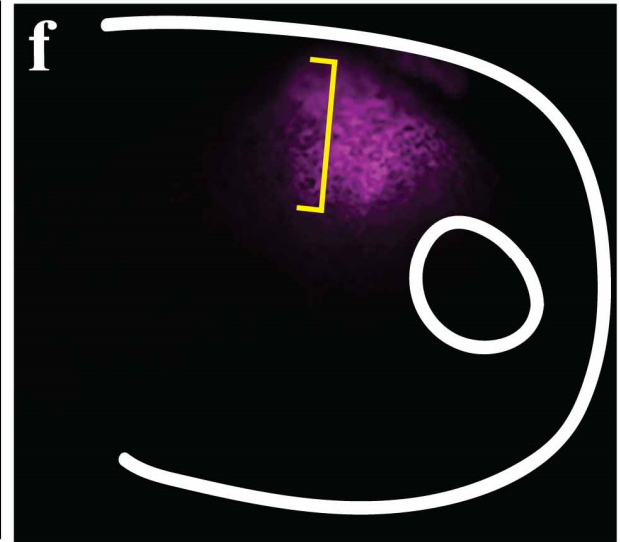

h

\% NC Migration

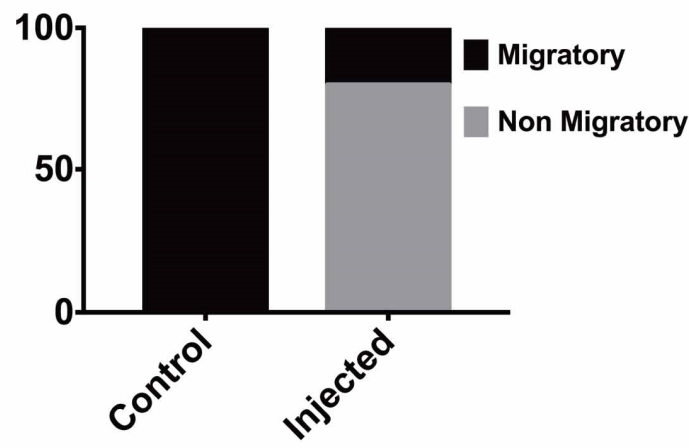


Figure 2. Examples of in vivo analysis of neural crest cell migration. a-b, Lateral views of stage-24 Xenopus embryos hybridised with a probe against slug (neural crest marker). a, representative example of a control embryo and b, contralateral side injected with a treatment that blocks NC migration. c, chart representing normalised NC migration. $d$, percentage of embryos displaying an effect on NC migration (in a typical experiment at least 30 embryos are used for in situ hybridisation and analysis of 3 independent experiments is required). e-f, Lateral views of stage-24 embryos grafted with (e) wild type (WT) NC or (f) NC injected with a treatment that blocks migration. $\mathrm{g}$, chart representing normalised NC migration. $\mathrm{h}$, percentage of embryos displaying an effect on NC migration (in a typical experiment at least 10 embryos are grafted and analysed per condition and 3 independent experiments are required). (a,b,e and f) Yellow brackets represent the distances used for the normalisation analysis. 

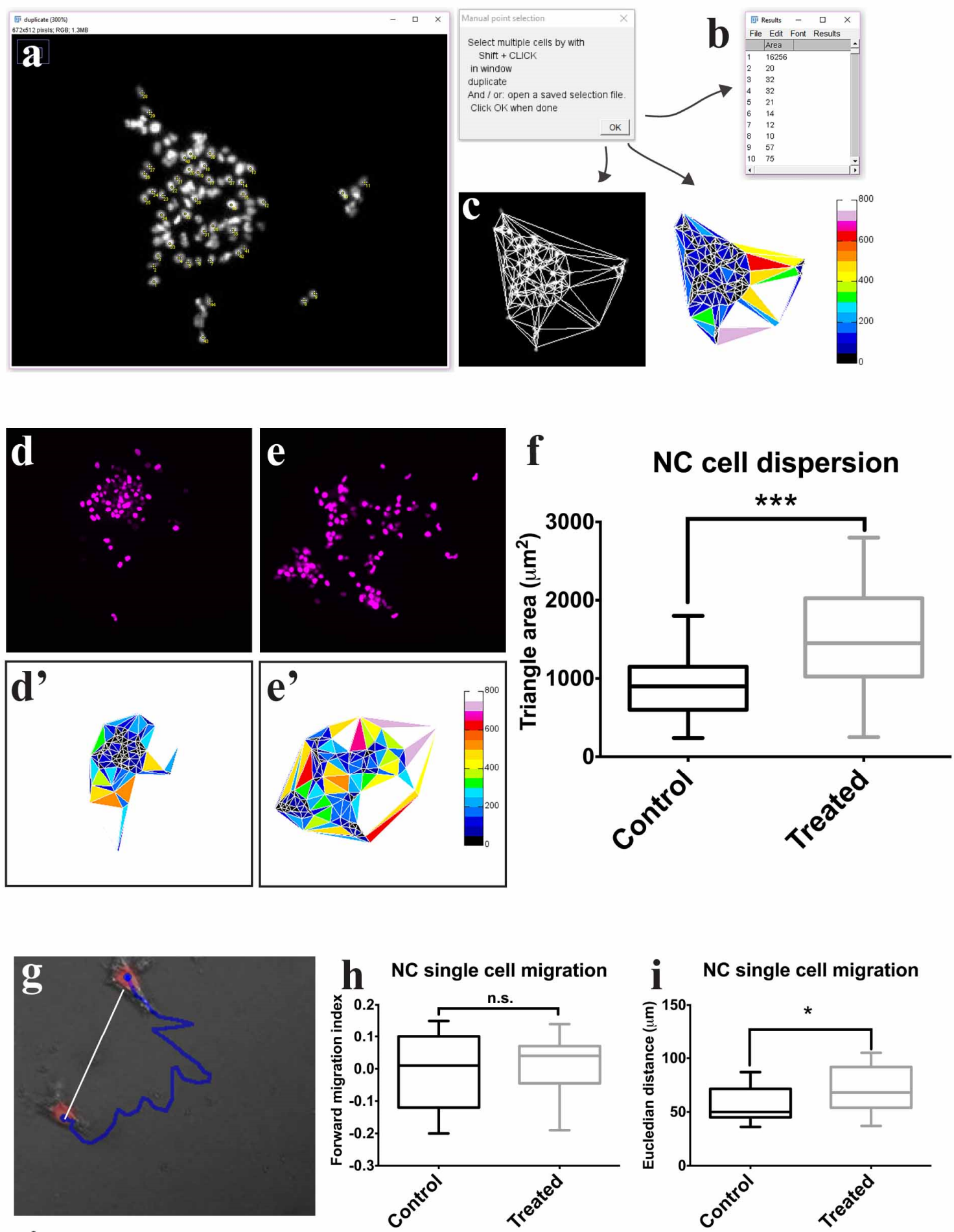

¡NC single cell migration

K NC single cell migration
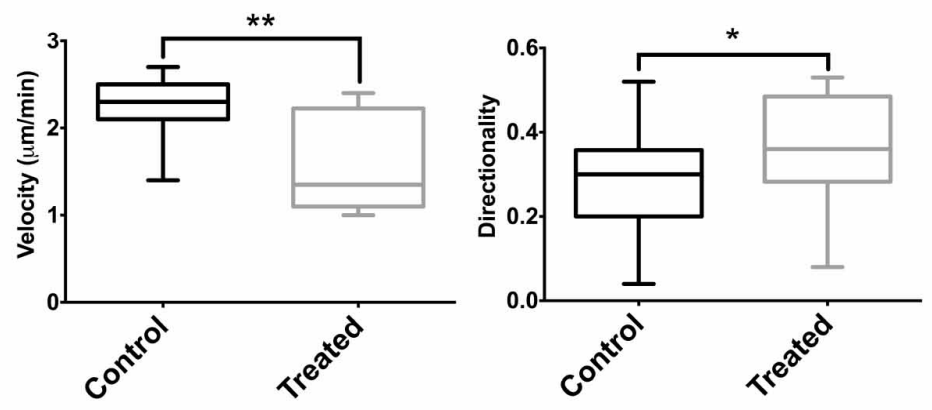

1 NC single cell migration

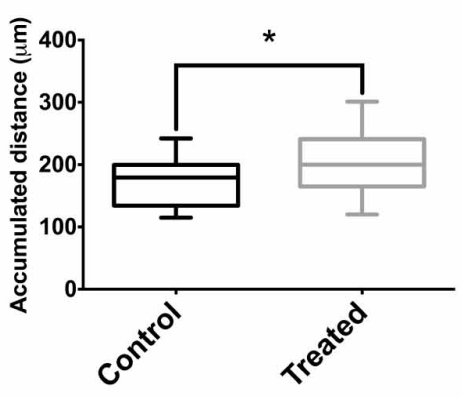


Figure 3. Examples of in vitro analysis of neural crest migration. (a-c) Cell dispersion analysis: Example image of a NC cell explant with point selection for some of the nuclei. Note that each point selection has an associated number. After all nuclei are selected, outputs include (b) a results file showing each triangle area that can be used for quantification, (c) a triangulation overlay with a color-coded triangulation image. (d-f) Cell dispersion presentation: Nuclei of (d) control and (e) treated NC cell explants along with color-coded triangulation areas for ( $\left.d^{\prime}\right)$ control and (e') treated examples and (f) chart representing quantification of triangle area. ( $g-l)$ Single cell migration analysis: (g) Example image of a NC cell track, blue line representing the tracked path; white line representing the Euclidean distance. Using the cell track data files, the Chemotaxis Tool allows you to quantify ( $h$ ) forward migration index (particularly useful for chemotaxis), (i) Euclidean distance, (j) cell velocity, (k) cell directionality and (I) accumulated distance. 